The Journal of Rheumatology 2021;48:5

doi: $10.3899 /$ jrheum. 201503

First Release January 152021

\section{Dr. Kiltz, et al reply}

\section{To the Editor:}

We thank Dr. Queiro and colleagues for their interest in our editorial review and the fascinating field of axial spondyloarthritis $(\mathrm{axSpA})^{1}$. Queiro and colleagues point out that disease-specific assessments used in routine care for patients with axSpA focus on assessment of disease activity and physical function but do not look much at the considerable variety of symptoms related to axSpA. We can only fully agree with this statement, as we already stressed in our editorial that "the management of patients with axSpA is especially challenging, since this complex disease entity has a wide variability of clinical signs and symptoms" ${ }^{2}$. Therefore, a standardized assessment is useful and often needed to address the wide range of potential impairments assessed by the Health Index (HI) that has been recently developed by the Assessment of Spondyloarthritis international Society (ASAS) ${ }^{2}$ - the first disease-specific in strument that is based on the In ternational Classification of Functioning, Disability and Health (ICF) concept, which takes impairments into account, not only for physical but also for emotional and social issues ${ }^{3}$. Thus, when studying global functioning in axSpA, all major domains of physical, emotional, and social functioning need to be assessed ${ }^{4}$. The ASAS HI is a standardized tool that increases the feasibility of such an assessment since it is an instrument that covers those domains "all in one"2,5 instead of having one instrument each for physical, emotional, and social functioning, all of which are assessed separately. This aspect seems to differ from the opinion of Queiro, et al, who stated that "in very busy clinics, it can be materially impossible to use all these tools due to obvious time constraints." Nevertheless, the ASAS HI has indeed not been designed for use in clinical routine but for clinical studies. Indeed, it was recently used in the Tight Control in Spondyloarthritis (TICOSPA) trial, in which the percentage of patients with a significant improvement in the ASAS HI score (> 30\%) over a 1-year follow-up was chosen as the main outcome ${ }^{6}$. However, a role also in clinical routine, as suggested by Queiro and colleagues ${ }^{1}$, seems possible but requires more studies to understand its usefulness in daily practice.
Uta Kiltz ${ }^{1}$ (D) MD, PhD, Rheumatologist

Daniel Wendling 2 (D), MD, PhD, Professor of Rheumatology, Head of

Department of Rheumatology, University Teaching Hospital

Juergen Braun ${ }^{1}[$, Professor of Rheumatology, Head of Department

${ }^{1}$ Rheumazentrum Ruhrgebiet, Herne, and Ruhr-Universität Bochum, Bochum, Germany;

${ }^{2}$ Centre Hospitalier Régional Universitaire de Besançon, and EA 4266, EPILAB, Université de Franche-Comté, Besançon, France.

The authors declare no conflicts of interest.

Address correspondence to Dr. U. Kiltz, Rheumazentrum Ruhrgebiet, Claudiusstr. 45, Herne, NRW 44649, Germany.

Email: uta.kiltz@elisabethgruppe.de.

\section{REFERENCES}

1. Kiltz U, Wendling D, Braun J. ASAS Health Index: the "all in one" for spondyloarthritis evaluation? J Rheumatol 2020;47:1457-60.

2. Kiltz U, van der Heijde D, Boonen A, Akkoc N, Bautista-Molano W, Burgos-Vargas R, et al. Measurement properties of the ASAS Health Index: results of a global study in patients with axial and peripheral spondyloarthritis. Ann Rheum Dis 2018;77:1311-7.

3. World Health Organization. The International Classification of Functioning, Disability and Health. 2001. [Internet. Accessed November 17, 2020.] Available from: www.who.int/classifications/ icf/en

4. Boonen A, Braun J, van der Horst Bruinsma IE, Huang F, Maksymowych W, Kostanjsek N, et al. ASAS/WHO ICF Core Sets for ankylosing spondylitis (AS): how to classify the impact of AS on functioning and health. Ann Rheum Dis 2010;69:102-7.

5. Kiltz U, van der Heijde D, Boonen A, Braun J. The ASAS Health Index (ASAS HI) - a new tool to assess the health status of patients with spondyloarthritis. Clin Exp Rheumatol 2014;5 Suppl 85:S105-8.

6. Molto A, López-Medina C, Van den Bosch F, Webers C, Dernis $\mathrm{E}$, van Gaalen F, et al. Cluster-randomized pragmatic clinical trial evaluating the potential benefit of a tight-control and treat-to-target strategy in axial spondyloarthritis: the results of the TICOSPA trial [abstract]. Ann Rheum Dis 2020;72 Suppl 10. 